\title{
Pulmonary mucormycosis
}

\section{mimicking as pulmonary}

\section{tuberculosis: A rare case report}

\author{
Divya Khanduja ${ }^{1 *}$, NC Kajal ${ }^{2}$, Rajbir Singh ${ }^{1}$ and Shakti \\ Sharma ${ }^{3}$
}

Received: 19 July, 2021

Accepted: 26 July, 2021

Published: 27 July, 2021

*Corresponding author: Divya Khanduja, Junior Resident, Department of Pulmonary Medicine, Government Medical College, Amritsar, Punjab, India, Tel: +91-9582969172; Email: divyakhandujalhmc@gmail. com, khanduja.divya@gmail.com

Keywords: Pulmonary mucormycosis; Tuberculosis; HIV; Air crescent sign

https://www.peertechzpublications.com

Check for updates

1Junior Resident, Department of Pulmonary Medicine, Government Medical College, Amritsar, Punjab, India

${ }^{2}$ Professor, Department of Pulmonary Medicine, Government Medical College, Amritsar, Punjab, India

${ }^{3}$ District TB Officer (DTO), Hoshiarpur, Punjab, India

\begin{abstract}
Pulmonary mucormycosis is an uncommon pulmonary fungal disease, which is commonly seen in immunocompromised individuals. It is caused by fungi of class Zygomycetes. It constitutes the third most common invasive fungal infection following aspergillosis and candidiasis. Risk factors include patients with hematological malignancies, diabetes mellitus, and immunocompromised states. It is difficult to diagnose early due to non-specific clinical presentation and delay in treatment associated with greater mortality. Here we report a case of 26-year-old male who presented with history of cough, breathlessness for past 2 months and, haemoptysis and fever for past 1-2 weeks. Patient has history of illicit intravenous drug abuse and previous history of Pulmonary Tuberculosis as a risk factor for immunosuppression in this case. As we know that Tuberculosis and HIV are highly prevalent in country like India. Patient had non-resolving opacification with cavitation on chest radiograph for which he was misdiagnosed as Pulmonary Tuberculosis. The diagnosis of Pulmonary Mucormycosis is bases upon demonstration of fungal hyphae in the clinical specimen. We highlight the importance of clinical suspicion in these cases for early diagnosis and early treatment initiation can reverse morbidity and mortality associated with Pulmonary Mucormycosis.
\end{abstract}

\section{Introduction}

Pulmonary mucormycosis is a rare disease caused by order Mucorales of class Zygomycetes, affecting immunocompromised individuals, both in developing and developed countries [1]. The term Zygomycosis, which was used for infections caused by fungi of the order Mucorales, has been discarded according to the recent taxonomic literature that abolished Zygomycetes as a class [2]. Mucorales fungi are ubiquitous, saprophytic and not fastidious fungi found on soil or decaying organic matter. The three genera that are most commonly associated with infections in the human, namely, Rhizopus, Mucor and Absidia (Lichtheimia) [3]. Rhino-orbitalcerebral and pulmonary infections are the most common manifestations caused by these fungi by the inhalation of spores. In 1876, the first case of Pulmonary mucormycosis was reported by Furbringer [4]. The prevalence of mucormycosis is estimated to be around 70 times higher in India than globally.
Diabetes mellitus is the most common risk factor, followed by haematological malignancy and solid-organ transplant. Other risk factors include illicit use of intravenous drugs, prolonged steroid use, persistent neutropenia, desferoxamine therapy. Patients with post-pulmonary tuberculosis and chronic kidney disease are additional emerging risk factors for developing mucormycosis in India [5]. There is spike in the cases of Mucormycosis due to COVID 19 infection as it is associated with impaired immune status in the infected patient. We are reporting a case of Pulmonary mucormycosis in an HIV seropositive patient, which was misdiagnosed as Pulmonary tuberculosis.

\section{Case presentation}

A 26-year-old male presented at emergency with complaints of cough with mucopurulent sputum and breathlessness for 2 months, haemoptysis and fever for 7 days. He was diagnosed with HIV 1-year back for which patient is on ART (anti-retroviral 
therapy) as patient has past history of intravenous drug abuse (heroin addict) 1year back for the duration of 9 months. He was treated for pulmonary tuberculosis thrice in past 3 years. He gave history of smoking for 4-5 years, alcoholic for 5 years. He was taking anti-tubercular treatment (Rifampicin, Isoniazid, Ethambutol, Pyrazinamide) for Pulmonary tuberculosis on clinico-radiological basis for last 10 days.

On examination, patient was emaciated. He was slight dyspnoeic without the use of accessory muscles, with a blood pressure of $120 / 70 \mathrm{mmHg}$, pulse rate of $94 / \mathrm{min}$, respiratory rate of $26 / \mathrm{min}$, and saturation of $92 \%$ on room air. On general physical examination, clubbing was present. On auscultation, bilateral bronchial breath sounds present on interscapular and infra-scapular areas increase vocal fremitus bilaterally.

Laboratory findings revealed haemoglobin of $12 \mathrm{~g} / \mathrm{dl}$, white blood count of 6,400 , ESR-71, RBS-110mg/dl, serum bilirubin-0.5, SGOT-45, SGPT-38, TSP-6.4, DSP-3.7, serum creatinine-0.8. His sputum for AFB on Ziehl-Neelson staining and gram stain and culture were negative. Induced sputum for fungus revealed fungal hyphae on $\mathrm{KOH}$ mount. Sputum for CBNAAT (Xpert MTB/RIF) showed MTB not detected. The nasopharyngeal swab sent for Covid 19 RTPCR testing was negative. Serology of HBsAg and HCV were negative.

Chest radiograph (Figure 1) showed bilateral heterogenous opacities on upper and middle zones bilaterally. Computed tomography (Figure 2) revealed multifocal areas of cavitation involving bilateral upper and lower lobes of lungs. Fungal balls in bilateral upper lobe cavities showing air crescent sign.

Owing to the unaffordability of patient, the patient denied for Bronchoscopy which was advised to him. Transthoracic needle aspiration from left-sided cavitary lesion was done, and aspirated sample sent for AFB smear, gram stain and culture, malignant cells and fungal smear examination. Aspirate was found to be negative for AFB and malignant cells. On $\mathrm{KOH}$ mount (Figure 3) we found broad aseptate thin-walled fungal hyphae with right angle branching, Rhizopus genus was found.

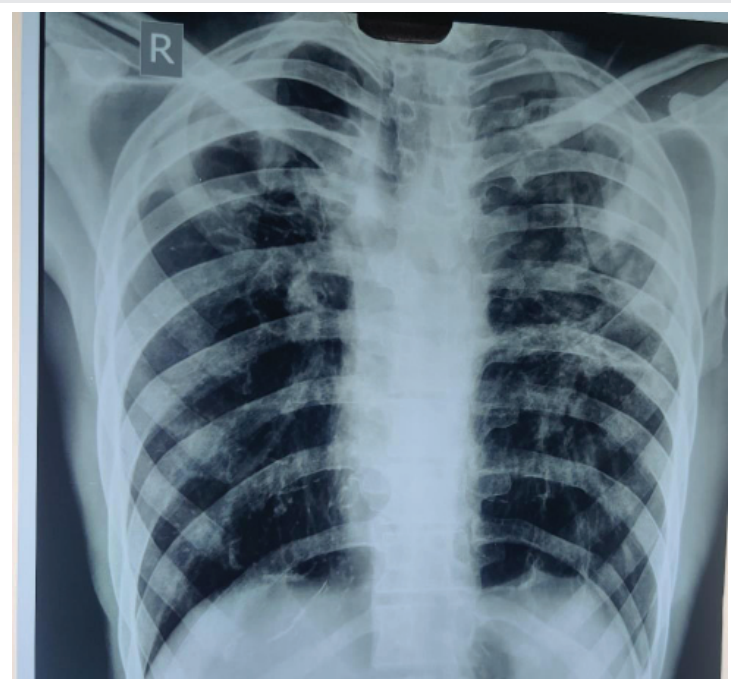

Figure 1: CXR PA view showed bilateral heterogenous opacities on upper and middle zones of both sides.

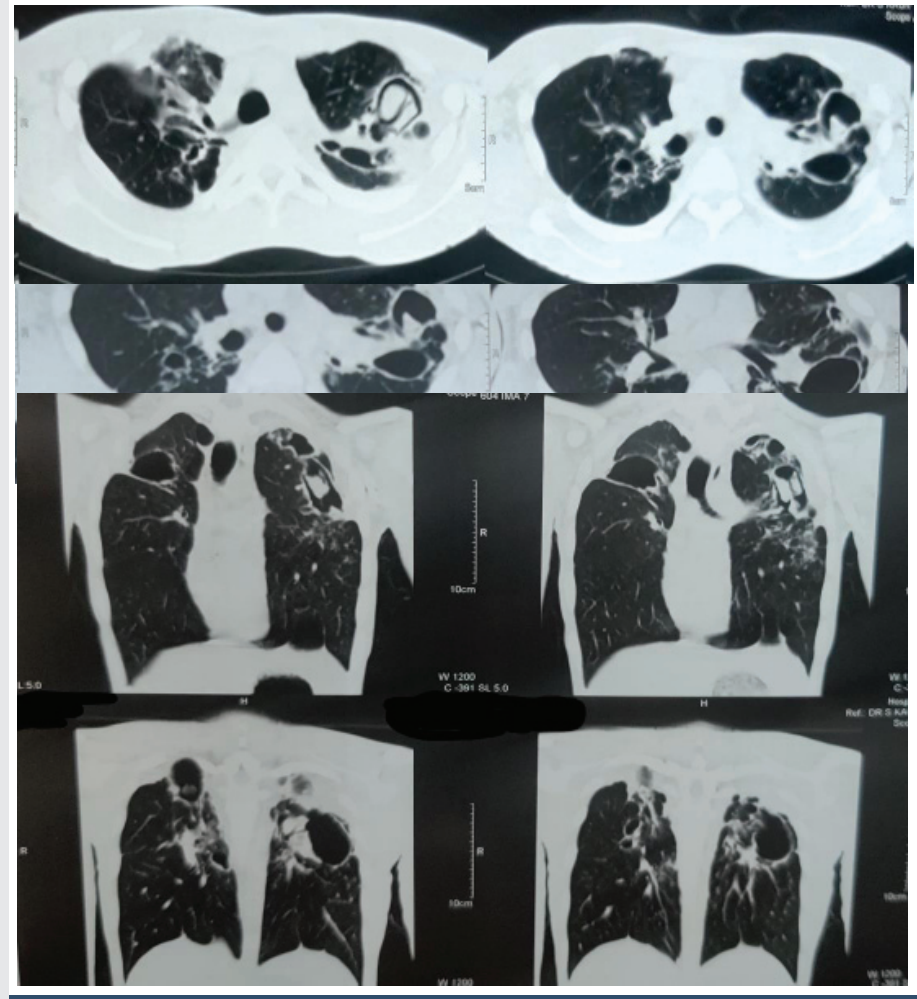

Figure 2: CECT Chest showed multifocal areas of cavitation involving bilateral upper and lower lobes of lungs. Fungal balls in bilateral upper lobe cavities showing air crescent sign.
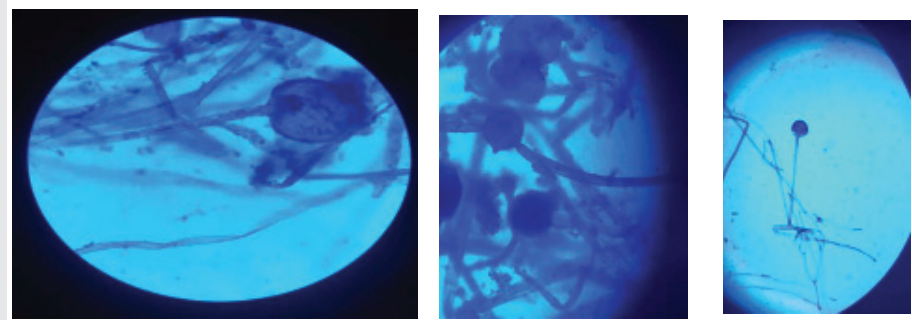

Figure 3: $\mathrm{KOH}$ mount showed broad aseptate thin-walled fungal hyphae with right angle branching, found to be genus Rhizopus.

Patient was started on intravenous Amphotericin-B at the dose of $5 \mathrm{mg} / \mathrm{kg} / \mathrm{day}$, patient was referred to cardiothoracic surgery department for further planned left sided upper lobectomy of patient.

\section{Discussion}

Mucormycosis is an opportunistic, angio-invasive fungal infection, affecting immunocompromised individuals. It is a rapidly progressive infection associated with high morbidity and mortality. In recent years, it has been observed that the epidemiology of mucormycosis is being changing as incidence has raised with new causative agents and changing susceptible population. It is very high in Asian countries as compared globally. Though diabetes mellitus is most common risk factor found in Asia as well as globally, post-tuberculosis and chronic renal failure are new risk groups emerging in developing countries. The rhino-orbital-cerebral form of mucormycosis is most commonly associated with diabetes mellitus, whereas, pulmonary mucormycosis seen in patients with haematological malignancy and transplant recipients [6]. Other risk factors 
include illicit use of intravenous drugs, prolonged steroid use, persistent neutropenia, desferoxamine therapy. In India, Postcovid mucormycosis cases have also been reported due to the ongoing pandemic [7]. The prevalence of mucormycosis is estimated to be around 70 times higher in India than globally, which were estimated to be at 0.02 to 9.5 cases (with a median of 0.2 cases) per 100,000 persons [5,6]. Patients with postpulmonary tuberculosis and chronic kidney disease are the emerging risk factor for developing mucormycosis in this country [5].

In our case, HIV seropositive due to illicit use of intravenous drug abuse (heroin addiction) is risk factor associated with the development of Pulmonary Mucormycosis. Moreover, HIV infection favoured a misleading diagnosis of other opportunistic infection such as Tuberculosis, aspergillosis, etc.

The clinical presentations of mucormycosis are classified on the basis of anatomic localisation, such as rhino-orbitalcerebral (ROCM), pulmonary, gastrointestinal, cutaneous, renal, and disseminated mucormycosis [8]. The ROCM type is the most common form of the disease in India, followed by the pulmonary and cutaneous types [9]; however, the pulmonary mucormycosis is the most common clinical presentation in developed countries [10]. Rhizopus arrhizus is the most common cause of mucormycosis in India, other agents like Rhizopus microsporus, Rhizopus homothallicus, and Apophysomyces variabilis are rising [6].

Pulmonary mucormycosis is the rapidly progressive infection that occur after inhalation of spores into respiratory tract or by hematogenous or lymphatic spread [11]. It may present with nonspecific symptoms like cough, dyspnoea, chest pain, and fever [11]. Most patients present with fever and haemoptysis which can be massive sometimes. Haemoptysis results from angioinvasion which results in infarction and necrosis of the tissue, can leads to cavitation and haemoptysis, if major vessel gets involved it may be fatal [12].

The diagnosis of mucormycosis is made by histopathology and direct microscopy along with culture of the respective clinical specimens [13]. On histopathological examination, mucormycosis species appear as broad, nonseptate hyphae with right angle branching. Patient suspected of Pulmonary mucormycosis should be differentiated from aspergillosis as on histopathological examination Aspergillus shows regular, septate hyphae with acute angle branching [14].

Radiologically, the appearance of pulmonary mucormycosis is non-specific. Chest radiograph is abnormal in $>80 \%$ of patients [15]. Most common radiographic finding include lobar and segmental consolidation, in some patients it can be multi-lobar in distribution. Other findings include groundglass lesions generally progress to consolidation, multiple pulmonary nodule or masses which may have ground-glass halo (halo sign), which may progress to reverse halo sign with central necrosis, rarely cavity formation, and the aircrescent sign. As the fungus is angio-invasive, it causes the vascular findings like pulmonary artery pseudoaneurysms, and abrupt termination of pulmonary artery branch appearing as vascular cut-off sign. It can spread to pleura, chest wall and mediastinum causing lymphadenopathy, surgical emphysema and pleural thickening or effusion. Cavitation is seen in $40 \%$ of cases, but the air-crescent sign is rarely seen [16]. The presence of the air-crescent sign is an ominous sign, thus surgical management should not be delayed. High-resolution CT chest is used to determine the extent of disease with high sensitivity in Pulmonary mucormycosis.

In pulmonary mucormycosis, early diagnosis is important for the patient's survival due to rapid clinical course of progression and angio-invasive nature of the disease. For the definitive diagnosis, hyphae of the fungus should be identified in the appropriate clinical specimen. The diagnostic techniques include percutaneous needle biopsy, open lung biopsy and pleural fluid culture. Fiberoptic bronchoscopy is a useful diagnostic method, and an adequate bronchoalveolar lavage specimen provides enough diagnostic material to form a cytological diagnosis [17]. Clinical presentation of Pulmonary mucormycosis is non-specific, thus it should be differentiated from other bacterial, viral and fungal pulmonary infections. Most importantly, Pulmonary mucormycosis should be differentiated from Invasive aspergillosis so that appropriate treatment should be given for patient's survival [16].

Treatment of pulmonary mucormycosis include medical treatment with the recommended antifungal therapy and extensive surgical debridement [18]. Surgical resection of the infected parenchyma should be considered an early intervention to improve survival, due to the limited penetration of antifungal to the affected necrotic tissues, that accompanies this infection. The recommended antifungal agent is liposomal amphotericin B, subsequently, posaconazole and isavuconazole are prescribed [19].

The major drawbacks in managing mucormycosis in India are a gap in treatment protocol and the financial constraints of patients that they cannot afford liposomal amphotericin B. Pulmonary Mucormycosis is a relatively uncommon disease in comparison with Pulmonary Tuberculosis which is highly prevalent disease in India especially in Patient Living with HIV Infection (PLHIV). Another drawback is over-reliance in chest radiograph for diagnosis of Pulmonary Tuberculosis. A high level of clinical suspicion is important in any patient, in the presence of appropriate clinical setting and a nonresolving pulmonary opacity with cavitation for considering invasive fungal infection as differential diagnosis in immunocompromised patients.

\section{Conclusion}

Mucormycosis is an opportunistic life-threatening infection mostly occurring in the immunocompromised host. Pulmonary mucormycosis should be suspected in immunocompromised patient like HIV infection in country like India, particularly when they present with non-resolving pulmonary opacification with cavitation despite being on anti-tubercular therapy and when patient was already been treated with anti-tubercular therapy for Pulmonary tuberculosis. High clinical suspicion is required for early diagnosis of patient. Early diagnosis and

Citation: Divya K, Kajal NC, Singh R, Sharma S (2021) Pulmonary mucormycosis mimicking as pulmonary tuberculosis: A rare case report. Arch Pulmonol Respir 
treatment of patient with surgical debridement and medical treatment with recommended antifungal drugs can improve outcome and survival in Pulmonary mucormycosis.

\section{References}

1. Ribes JA, Vanover-Sams CL, Baker DJ (2000) Zygomycetes in human disease. Clin Microbiol Rev 13: 236-301. Link: https://bit.ly/2URigC5

2. Hibbett DS, Binder M, Bischoff JF, Blackwell M, Cannon PF, et al. (2007) A higher-level phylogenetic classification of the Fungi. Mycol Res 111: 509-547. Link: https://bit.ly/3rHDcYs

3. Spellberg B, Edwards J, Ibrahim A (2005) Novel perspectives on mucormycosis: Pathophysiology, presentation and management. Clin Microbiol Rev 18: 556569. Link: https://bit.ly/2TFZKfC

4. Fürbringer $P$ (1876) Observations on pulmonary mucormycosis in humans Virchows Arch Path Anat 66: 330-365.

5. Prakash H, Chakrabarti A (2021) Epidemiology of Mucormycosis in India. Microorganisms 9: 523. Link: https://bit.ly/3BHOSR1

6. Prakash $\mathrm{H}$, Chakrabarti A (2019) Global Epidemiology of Mucormycosis. J Fungi (Basel) 5: 26. Link: https://bit.ly/3x5HxWf

7. Garg D, Muthu V, Sehgal IS, Ramachandran R, Kaur H, et al. (2021) Coronavirus Disease (Covid-19) Associated Mucormycosis (CAM): Case Report and Systematic Review of Literature. Mycopathologia 186: 289-298. Link: https://bit.ly/3eVMWsF

8. Jeong W, Keighley C, Wolfe R, Lee WL, Slavin MA, et al. (2019) The epidemiology and clinical manifestations of mucormycosis: A systematic review and meta-analysis of case reports. Clin Microbiol Infect 25: 26-34. Link: https://bit.ly/3BPQLd5

9. Prakash H, Ghosh AK, Rudramurthy SM, Singh P, Xess I, et al. (2019) A prospective multicenter study on mucormycosis in India: Epidemiology, diagnosis, and treatment. Med Mycol 57: 395-402. Link: https://bit.ly/3i58dSR
10. Skiada A, Pagano L, Groll A, Zimmerli S, Dupont B, et al. (2011) Zygomycosis in Europe: Analysis of 230 cases accrued by the registry of the European Confederation of Medical Mycology (ECMM) Working Group on Zygomycosis between 2005 and 2007. Clin Microbiol Infect 17: 1859-1867. Link: https://bit.ly/36XP3bj

11. Serris A, Danion F, Lanternier $F$ (2019) Disease entities in mucormycosis. $J$ Fungi 5: 23. Link: https://bit.ly/3rHODB1

12. Garg R, Marak RSK, Verma SK, Singh J, Sanjay, et al. (2008) pulmonary mucormycosis mimicking as pulmonary tuberculosis: a case report. Lung India 25: 129-131. Link: https://bit.ly/3y6clrn

13. Challa S, Uppin SG, Uppin MS, Paul RT, Prayaga AK, et al. (2011) pulmonary zygomycosis: a clinicopathological study. Lung India 28: 25-29. Link: https://bit.ly/2VawH4f

14. Song JG, Kang SH, Jung BW, Oh HS, Kim MJ, et al. (2016) Invasive pulmonary aspergillosis histologically mimicking mucormycosis. Ewha Medical Journa 39: 65-68. Link: https://bit.ly/3eVP6Zm

15. Donado-Uña JR, Díaz-Hellín V, López-Encuentra A, Echave-Sustaeta JM (2002) Persistent cavitations in pulmonary mucormycosis after apparently successful amphotericin B. Eur J Cardiothorac Surg 21: 940-942. Link: https://bit.ly/3kZqByi

16. Chung JH, Godwin JD, Chien JW, Pipavath SJ (2010) Case 160: Pulmonary mucormycosis. Radiology 256: 667-670. Link: https://bit.ly/371Jbh2

17. Al-Abbadi MA, Russo K, Wilkinson EJ (1997) pulmonary mucormycosis diagnosed by bronchoalveolar lavage: A case report and review of the literature. Pediatr Pulmonol 23: 222-225. Link: https://bit.ly/2TzujU2

18. Tedder M, Spratt JA, Anstadt MP, Hegde SS, Tedder SD, et al. (1994) pulmonary mucormycosis: results of medical and surgical therapy. Ann Thorac Surg 57: 1044-1050. Link: https://bit.ly/3rzL4ee

19. Cornely OA, Alastruey-Izquierdo A, Arenz D, Chen SCA, Dannaoui E, et al. (2019) Global guideline for the diagnosis and management of mucormycosis: An initiative of the European Confederation of Medical Mycology in cooperation with the Mycoses Study Group Education and Research Consortium. Lancet Infect Dis 19: e405-e421. Link: https://bit.ly/3I9FUEX

\section{Discover a bigger Impact and Visibility of your article publication with}

\section{Peertechz Publications}

\section{Highlights}

* Signatory publisher of ORCID

* Signatory Publisher of DORA (San Francisco Declaration on Research Assessment)

* Articles archived in worlds' renowned service providers such as Portico, CNKI, AGRIS, TDNet, Base (Bielefeld University Library), CrossRef, Scilit, J-Gate etc.

* Journals indexed in ICMJE, SHERPA/ROMEO, Google Scholar etc.

- OAI-PMH (Open Archives Initiative Protocol for Metadata Harvesting)

- Dedicated Editorial Board for every journal

* Accurate and rapid peer-review process

* Increased citations of published articles through promotions

* Reduced timeline for article publication

Submit your articles and experience a new surge in publication services (https://www.peertechz.com/submission).

Peertechz journals wishes everlasting success in your every endeavours.

Copyright: @ 2021 Divya K, et al. This is an open-access article distributed under the terms of the Creative Commons Attribution License, which permits unrestricted use distribution, and reproduction in any medium, provided the original author and source are credited. 